\title{
Performance of an Antigen-Based Test for Asymptomatic and Symptomatic SARS-CoV-2 Testing at Two University Campuses - Wisconsin, September-October 2020
}

\begin{abstract}
Ian W. Pray, PhD $1,2,3$,*; Laura Ford, PhD ${ }^{1,2, *}$; Devlin Cole, MD ${ }^{3,4}$; Christine Lee, PhD ${ }^{1,5}$, John Paul Bigouette, PhD ${ }^{1,2}$; Glen R. Abedi, $\mathrm{MPH}^{1}$; Dena Bushman, MSN, MPH ${ }^{1,2}$; Miranda J. Delahoy, $\mathrm{PhD}^{1,2}$; Dustin Currie, $\mathrm{PhD}^{1,2}$; Blake Cherney, MS ${ }^{1}$; Marie Kirby, PhD ${ }^{1}$; Geroncio Fajardo, $\mathrm{MD}^{1}$; Motria Caudill, PhD ${ }^{1,6}$; Kimberly Langolf, MS ${ }^{7}$; Juliana Kahrs, MS ; Patrick Kelly, MD ${ }^{4,8}$; Collin Pitts, MD ${ }^{4,8}$; Ailam Lim, $\mathrm{PhD}^{9}$; Nicole Aulik, PhD ; Azaibi Tamin, $\mathrm{PhD}^{1}$; Jennifer L. Harcourt, $\mathrm{PhD}^{1}$; Krista Queen, $\mathrm{PhD}^{1}$; Jing Zhang, $\mathrm{PhD}^{1}$; Brett Whitaker, $\mathrm{PhD}^{1}$; Hannah Browne $^{1}$; Magdalena Medrzycki, PhD $^{1}$; Patricia Shewmaker, PhD ${ }^{1}$; Jennifer Folster, PhD ${ }^{1}$; Bettina Bankamp, PhD ${ }^{1}$; Michael D. Bowen, PhD ${ }^{1}$; Natalie J. Thornburg, $\mathrm{PhD}^{1}$; Kimberly Goffard, MBA ${ }^{10}$; Brandi Limbago, $\mathrm{PhD}^{1}$; Allen Bateman, $\mathrm{PhD}^{7,11}$; Jacqueline E. Tate, PhD ${ }^{1}$; Douglas Gieryn ${ }^{10}$; Hannah L. Kirking, MD ${ }^{1}$; Ryan Westergaard, MD, PhD ${ }^{3,4}$; Marie Killerby, VetMB ${ }^{1}$; CDC COVID-19 Surge Laboratory Group
\end{abstract}

Antigen-based tests for SARS-CoV-2, the virus that causes coronavirus disease 2019 (COVID-19), are inexpensive and can return results within 15 minutes (1). Antigen tests have received Food and Drug Administration (FDA) Emergency Use Authorization (EUA) for use in asymptomatic and symptomatic persons within the first 5-12 days after symptom onset (2). These tests have been used at U.S. colleges and universities and other congregate settings (e.g., nursing homes and correctional and detention facilities), where serial testing of asymptomatic persons might facilitate early case identification (3-5). However, test performance data from symptomatic and asymptomatic persons are limited. This investigation evaluated performance of the Sofia SARS Antigen Fluorescent Immunoassay (FIA) (Quidel Corporation) compared with real-time reverse transcription-polymerase chain reaction (RT-PCR) for SARS-CoV-2 detection among asymptomatic and symptomatic persons at two universities in Wisconsin. During September 28-October 9, a total of 1,098 paired nasal swabs were tested using the Sofia SARS Antigen FIA and real-time RT-PCR. Virus culture was attempted on all antigenpositive or real-time RT-PCR-positive specimens. Among $871(79 \%)$ paired swabs from asymptomatic participants, the antigen test sensitivity was $41.2 \%$, specificity was $98.4 \%$, and in this population the estimated positive predictive value (PPV) was 33.3\%, and negative predictive value (NPV) was $98.8 \%$. Antigen test performance was improved among 227 (21\%) paired swabs from participants who reported one or more symptoms at specimen collection (sensitivity $=80.0 \%$; specificity $=98.9 \% ; \mathrm{PPV}=94.1 \% ; \mathrm{NPV}=95.9 \%)$. Virus was isolated from 34 (46.6\%) of 73 antigen-positive or real-time RT-PCR-positive nasal swab specimens, including two of 18 that were antigen-negative and real-time RT-PCR-positive (false-negatives). The advantages of antigen tests such as low cost and rapid turnaround might allow for rapid identification of infectious persons. However, these advantages need to be

\footnotetext{
* These authors contributed equally to this report.
}

balanced against lower sensitivity and lower PPV, especially among asymptomatic persons. Confirmatory testing with an FDA-authorized nucleic acid amplification test (NAAT), such as RT-PCR, should be considered after negative antigen test results in symptomatic persons, and after positive antigen test results in asymptomatic persons (1).

Paired nasal swabs were collected from students, faculty, staff members, and other affiliates ${ }^{\dagger}$ at two Wisconsin university campuses during university-based testing programs. At university A, all persons tested (screening or diagnostic) at the university testing center during October 1-9 were eligible to participate. At university $\mathrm{B}$, only students who were quarantined during September 28-October 6 after exposure to persons with COVID-19 could participate.

All participants completed a questionnaire and provided information on demographic characteristics, current and past (14 days) symptoms, ${ }^{\S}$ and recent exposure ${ }^{\$}$ to persons with COVID-19. For each participant, two mid-turbinate nasal swabs were collected by health care personnel at university A and were self-collected under supervision at university B. Both nostrils were sampled with each of the two swabs. Swabs for antigen testing were analyzed according to the manufacturer's instructions. ${ }^{* *}$ Swabs for real-time RT-PCR were stored in viral transport media at $39^{\circ} \mathrm{F}\left(4^{\circ} \mathrm{C}\right)$ and analyzed within 24-72 hours of collection. At university A, real-time RT-PCR was performed using the CDC 2019-nCoV real-time RT-PCR

\footnotetext{
$\dagger$ Other affiliates were participants who did not mark "student" or "staff" on the questionnaire (they selected "other" or did not respond); the majority of these persons were family members of staff members.

$\$$ Symptom list was based on the interim position statement for COVID-19 case definitions from the Council of State and Territorial Epidemiologists, updated August 7, 2020. Clinical criteria for COVID-19 included fever, cough, shortness of breath, fatigue, sore throat, headache, muscle aches, chills, nasal congestion, difficulty breathing, diarrhea, nausea, vomiting, abdominal pain, rigors, loss of taste, and loss of smell. https://cdn.ymaws.com/www.cste. org/resource/resmgr/ps/positionstatement2020/Interim-20-ID-02_ COVID-19.pdf.

S Recent exposure was defined as being within 6 feet of a person with a COVID-19 diagnosis for $\geq 15$ minutes in the past 14 days.

** https://www.fda.gov/media/137885/download.
} 
diagnostic panel $(6)$, with cycle threshold $(\mathrm{Ct})$ values reported for the N1 and N2 viral nucleocapsid protein gene regions. At university B, real-time RT-PCR was performed using the TaqPath COVID-19 Combo Kit (Thermo Fisher Scientific). Viral culture $^{\dagger \dagger}(7)$ was attempted on residual RT-PCR specimens if the RT-PCR or antigen test result was positive.

Statistical analyses were performed using Stata (version 16.1; StataCorp). Sensitivity, specificity, PPV, and NPV were calculated for antigen testing compared with real-time RT-PCR results. Ninety-five percent confidence intervals (CIs) were calculated using the exact binomial method; t-tests were used for $\mathrm{Ct}$ value comparisons ${ }^{\mathbb{S}}$; p-values $<0.05$ were considered statistically significant. This investigation was reviewed by $\mathrm{CDC}$ and was conducted consistent with applicable federal law and CDC policy.99 Ethical review boards at both universities determined the activity to be nonresearch public health surveillance (2).

Among a total of 1,105 total nasal swab pairs submitted, seven $(0.06 \%)$ were excluded for having inconclusive antigen or real-time RT-PCR results. Test comparisons were performed on 1,098 paired nasal swabs (2,196 total swabs), including 1,051 pairs (95.7\%) from university A and 47 pairs (4.3\%) from university B (Table 1). Among the 1,098 pairs evaluated, 994 (90.5\%) were provided by students aged $17-53$ years $($ median $=19$ years $), 82(7.5 \%)$ by university faculty or staff members aged 22-63 years (median $=38$ years), and $22(2.0 \%)$ by other university affiliates aged $15-64$ years (median $=29$ years). Fifty-seven persons participated more than once on different testing days. Overall, 453 (41.3\%) participants were male, and 917 (83.5\%) were non-Hispanic White. At specimen collection, 227 (20.7\%) participants reported experiencing one or more COVID-19 symptoms, and $871(79.3 \%)$ reported no symptoms.

Among 227 paired specimens from symptomatic participants, $34(15.0 \%)$ were antigen-positive, and $40(17.6 \%)$ were realtime RT-PCR-positive. The median interval from symptom onset to specimen collection was 3 days (interquartile range $=1-6$ days; $7.5 \%$ missing). Among symptomatic participants, antigen testing sensitivity was $80.0 \%$ (32 of 40), specificity was $98.9 \%$ (185 of 187), PPV was $94.1 \%$ (32 of 34),

\footnotetext{
$\dagger_{\dagger}$ Specimens were used to perform a limiting-dilution inoculation of Vero CCL-81 cells, and cultures showing evidence of cytopathic effect (CPE) were tested by real-time RT-PCR for the presence of SARS-CoV-2 RNA. Viral recovery was defined as any culture in which the first passage had an $\mathrm{N} 1 \mathrm{Ct}$ at least twofold lower than the corresponding clinical specimen.

$\$ \$$ Ct values from real-time RT-PCR were only compared for specimens collected at university A that were analyzed with the CDC 2019-nCoV real-time RT-PCR diagnostic panel for detection of SARS-CoV-2.

9945 C.F.R. part 46.102(1)(2), 21 C.F.R. part 56; 42 U.S.C. Sect. 241(d); 5 U.S.C. Sect. 552a; 44 U.S.C. Sect. 3501 et seq.
}

and NPV was $95.9 \%$ (185 of 193) (Table 2). For specimens collected within 5 days of reported symptom onset $(72.4 \%$; 152 of 210 ), sensitivity was $74.2 \%$ (23 of 31 ), and specificity was $99.2 \%$ (120 of 121).

Among 871 paired specimens from asymptomatic participants, $21(2.4 \%)$ were antigen-positive and $17(2.0 \%)$ were real-time RT-PCR-positive. Antigen testing sensitivity was $41.2 \%$ (seven of 17 ), specificity was $98.4 \%$ (840 of 854 ), PPV was $33.3 \%$ (seven of 21), and NPV was $98.8 \%$ (840 of $850)$. Test performance was not significantly $(\mathrm{p}>0.05)$ different when excluding $53(6.1 \%)$ of 871 participants who were asymptomatic at the time of testing but had reported one or more symptoms in the preceding 14 days.

Sixteen paired swabs were antigen-positive and real-time RT-PCR-negative (i.e., false-positive), including 14 (66.7\%) of 21 positive antigen results from asymptomatic participants and two (5.9\%) of 34 from symptomatic participants. Eight of the 16 false-positive results were recorded during a 1-hour period at university $\mathrm{A}$. In this instance, a series of consecutive positive results in asymptomatic persons was noted, and investigators offered repeat antigen testing to the affected participants. Six of eight participants were reswabbed within 1 hour, and all six received negative test results on a second antigen test. All eight initial paired swabs from these participants were negative on real-time RT-PCR. Because no user errors could be identified, the false-positive results were included in analysis. Eighteen false-negative antigen test results were obtained, including 10 $(58.8 \%)$ of 17 real-time RT-PCR-positive tests from asymptomatic participants, and eight $(20.0 \%)$ of 40 from symptomatic participants. All false-negative results from symptomatic participants were from specimens collected $<5$ days after onset of symptoms (median $=2$ days). Ct values for specimens with false-negative antigen results were significantly higher compared with antigen- and real-time RT-PCR-positive specimens (mean N1 Ct $=32.3$ versus 23.7; $\mathrm{p}<0.01$ ) (Figure).

Virus was recovered from $34(46.6 \%)$ of 73 positive specimens, including $32(82.1 \%)$ of 39 specimens with concordant positive results and two (11.1\%) of 18 with false-negative antigen results; no virus was recovered from 16 specimens with false-positive antigen test results. The two specimens with false-negative antigen results that were culture-positive were from two symptomatic participants who had specimens collected at day 2 and day 4 after symptom onset.***

\footnotetext{
*** The participant with a false-negative result 2 days after symptom onset had a repeat specimen 2 days later; the results of testing were positive by antigen test and by real-time RT-PCR.
} 
TABLE 1. Characteristics and symptoms of persons providing paired nasal swabs $(\mathrm{N}=1,098)$, by results for SARS-CoV-2 real-time reverse transcription-polymerase chain reaction (RT-PCR) and Sofia SARS Antigen Fluorescent Immunoassay testing† - two universities, Wisconsin, September-October 2020

\begin{tabular}{|c|c|c|c|c|c|}
\hline \multirow[b]{2}{*}{ Characteristic } & \multicolumn{5}{|c|}{ No (\%) } \\
\hline & $\begin{array}{l}\text { True positives } \\
\qquad(\mathrm{N}=39)\end{array}$ & $\begin{array}{l}\text { False negatives } \\
\qquad(\mathrm{N}=18)\end{array}$ & $\begin{array}{l}\text { False positives } \\
\qquad(N=16)\end{array}$ & $\begin{array}{l}\text { True negatives } \\
\qquad(\mathrm{N}=1,025)\end{array}$ & $\begin{array}{c}\text { Total } \\
(\mathrm{N}=1,098)\end{array}$ \\
\hline \multicolumn{6}{|l|}{ Testing site } \\
\hline University $\mathrm{A}^{\S}$ & $37(94.9)$ & $17(94.4)$ & $15(93.8)$ & $982(95.8)$ & $1,051(95.7)$ \\
\hline University B & $2(5.1)$ & $1(5.6)$ & $1(6.3)$ & $43(4.2)$ & $47(4.3)$ \\
\hline \multicolumn{6}{|l|}{ Sex } \\
\hline Male & $16(41.0)$ & $9(50.0)$ & $12(75.0)$ & $416(40.6)$ & $453(41.3)$ \\
\hline Female & $23(59.0)$ & $9(50.0)$ & $4(25.0)$ & $609(59.4)$ & $645(58.7)$ \\
\hline \multicolumn{6}{|l|}{ Age group (yrs) } \\
\hline $15-24^{* *}$ & $35(89.7)$ & $16(88.9)$ & $11(68.8)$ & $909(88.7)$ & $971(88.4)$ \\
\hline$\geq 25$ & $4(10.3)$ & $2(11.1)$ & $5(31.3)$ & $116(11.3)$ & $127(11.6)$ \\
\hline \multicolumn{6}{|l|}{ Race/Ethnicity ${ }^{\dagger \dagger}$} \\
\hline White & 31 (79.5) & $17(94.4)$ & $12(75.0)$ & $857(83.6)$ & $917(83.5)$ \\
\hline Hispanic/Latino & $6(15.4)$ & $0(0)$ & $1(6.3)$ & $54(5.3)$ & $61(5.6)$ \\
\hline Black/African-American & $0(0)$ & $1(5.6)$ & $2(12.5)$ & $26(2.5)$ & $29(2.6)$ \\
\hline Asian/Pacific Islander & $0(0)$ & $0(0)$ & $0(0)$ & $49(4.8)$ & $49(4.5)$ \\
\hline American Indian/Alaska Native & $0(0)$ & $0(0)$ & $0(0)$ & $3(0.3)$ & $3(0.3)$ \\
\hline Other/Unknown/Multiple races & $2(5.1)$ & $0(0)$ & $1(6.3)$ & $36(3.5)$ & $39(3.6)$ \\
\hline \multicolumn{6}{|l|}{ University status } \\
\hline Student & 35 (89.7) & $17(94.4)$ & $13(81.3)$ & $929(90.6)$ & $994(90.5)$ \\
\hline Faculty or staff member & $4(10.3)$ & $1(5.6)$ & $3(18.8)$ & $74(7.2)$ & $82(7.5)$ \\
\hline Other affiliate or unknown ${ }^{\S}$ & $0(0)$ & $0(0)$ & $0(0)$ & $22(2.2)$ & $22(2.0)$ \\
\hline \multicolumn{6}{|l|}{ Exposure $^{\text {ๆी }}$ to a COVID-19 case } \\
\hline Been in close contact in the past 14 days & $13(33.3)$ & $9(50.0)$ & $4(25.0)$ & $128(12.5)$ & $154(14.0)$ \\
\hline \multicolumn{6}{|l|}{ Quarantine status } \\
\hline Quarantined at time of specimen collection & $17(43.6)$ & $6(33.3)$ & $3(18.8)$ & $109(10.6)$ & $135(12.3)$ \\
\hline $\begin{array}{l}\text { Time between quarantine initiation to } \\
\text { specimen collection, median days (range) }\end{array}$ & $1(0-8)$ & $3.5(0-6)$ & $1(0-4)$ & $4(0-28)$ & $4(0-28)$ \\
\hline \multicolumn{6}{|l|}{ Reported symptoms } \\
\hline No current symptoms & $7(17.9)$ & $10(55.6)$ & $14(87.5)$ & $840(82.0)$ & $871(79.3)$ \\
\hline One or more symptoms in the past 14 days & $2(28.6)$ & $1(10.0)$ & $0(0)$ & $50(6.0)$ & $53(6.1)$ \\
\hline No symptoms in the past 14 days & $5(71.4)$ & $9(90.0)$ & $14(100.0)$ & $790(94.0)$ & 818 (93.9) \\
\hline
\end{tabular}

See table footnotes on the next page.

\section{Discussion}

The Sofia SARS Antigen FIA received FDA EUA on May 8, 2020, for use in symptomatic persons within 5 days of symptom onset (2). In this investigation, among persons reporting COVID-19-compatible symptoms at specimen collection, the test was less accurate (sensitivity $=80.0 \%$; specificity $=98.9 \%)$ than reported in the FDA EUA $($ sensitivity $=96.7 \%$; specificity $=100 \%)(2)$. Two of eight specimens from symptomatic persons that had false-negative antigen test results were positive by viral culture, indicating that potentially infectious persons might not be detected by antigen testing. To reduce the impact of false-negative antigen test results, confirmatory testing with an FDA-authorized NAAT, such as RT-PCR, should be considered following negative antigen test results in symptomatic persons (1).

Among asymptomatic participants, antigen test sensitivity was $41.2 \%$, specificity was $98.4 \%$, and PPV in this population was $33.3 \%$. This low PPV was observed despite a relatively high prevalence of SARS-CoV-2 in this population (5.2\% prevalence overall; $2.0 \%$ among asymptomatic persons), suggesting that PPV could be even lower when using this antigen test among populations with lower expected SARS-CoV-2 prevalence. To account for false-positive results when using antigen tests for asymptomatic screening, confirmatory NAAT testing should be considered following positive antigen test results in asymptomatic persons, particularly when pretest probability of SARS-CoV-2 infection is low (1). The NPV of antigen testing among asymptomatic participants was $98.8 \%$, and virus was not cultured from asymptomatic participants with antigen-negative results, indicating that asymptomatic persons with negative antigen results are unlikely to be infected with SARS-CoV-2 and would not require confirmatory NAAT (1).

The findings in this report are subject to at least four limitations. First, participants were predominantly young adults in university settings where ongoing serial testing was being conducted. Antigen test performance might differ in other 
TABLE 1. (Continued) Characteristics and symptoms of persons providing paired nasal swabs $(\mathrm{N}=1,098),{ }^{*}$ by results for SARS-CoV-2 real-time reverse transcription-polymerase chain reaction (RT-PCR) and Sofia SARS Antigen Fluorescent Immunoassay testingt - two universities, Wisconsin, September-October 2020

\begin{tabular}{|c|c|c|c|c|c|}
\hline \multirow[b]{2}{*}{ Characteristic } & \multicolumn{5}{|c|}{ No (\%) } \\
\hline & $\begin{array}{l}\text { True positives } \\
\qquad(\mathrm{N}=39)\end{array}$ & $\begin{array}{l}\text { False negatives } \\
\qquad(\mathrm{N}=18)\end{array}$ & $\begin{array}{l}\text { False positives } \\
\qquad(N=16)\end{array}$ & $\begin{array}{l}\text { True negatives } \\
\qquad(\mathrm{N}=1,025)\end{array}$ & $\begin{array}{c}\text { Total } \\
(\mathrm{N}=1,098)\end{array}$ \\
\hline One or more current symptoms & $32(82.1)$ & $8(44.4)$ & $2(12.5)$ & $185(18.0)$ & $227(20.7)$ \\
\hline Nasal congestion & $24(75.0)$ & $2(25.0)$ & $1(50.0)$ & $87(47.0)$ & $114(50.2)$ \\
\hline Sore throat & $12(37.5)$ & $5(62.5)$ & $1(50.0)$ & $79(42.7)$ & $97(42.7)$ \\
\hline Headache & $17(53.1)$ & $3(37.5)$ & $1(50.0)$ & $66(35.7)$ & $87(38.3)$ \\
\hline Cough & $18(56.3)$ & $6(75.0)$ & $1(50.0)$ & $45(24.3)$ & $70(30.8)$ \\
\hline Fatigue & $14(43.8)$ & $3(37.5)$ & $1(50.0)$ & $42(22.7)$ & $60(26.4)$ \\
\hline Muscle aches & $11(34.4)$ & $2(25.0)$ & $0(0)$ & $30(16.2)$ & $43(18.9)$ \\
\hline Shortness of breath & $7(21.9)$ & $1(12.5)$ & $0(0)$ & $16(8.6)$ & $24(10.6)$ \\
\hline Chills & $4(12.5)$ & $0(0)$ & $0(0)$ & $14(7.6)$ & $18(7.9)$ \\
\hline Diarrhea & $3(9.4)$ & $0(0)$ & $0(0)$ & $15(8.1)$ & $18(7.9)$ \\
\hline Nausea or vomiting & $3(9.4)$ & $0(0)$ & $0(0)$ & $14(7.6)$ & $17(7.5)$ \\
\hline Loss of taste & $8(25.0)$ & $2(25.0)$ & $1(50.0)$ & $3(1.6)$ & $14(6.2)$ \\
\hline Loss of smell & $8(25.0)$ & $2(25.0)$ & $1(50.0)$ & $2(1.1)$ & $13(5.7)$ \\
\hline Fever & $6(18.8)$ & $0(0)$ & $0(0)$ & $5(2.7)$ & $11(4.8)$ \\
\hline Difficulty breathing & $3(9.4)$ & $0(0)$ & $0(0)$ & $8(4.3)$ & $11(4.8)$ \\
\hline Abdominal pain & $1(3.1)$ & $0(0)$ & $0(0)$ & $6(3.2)$ & $7(3.1)$ \\
\hline Rigors & $0(0)$ & $0(0)$ & $0(0)$ & $0(0)$ & $0(0.0)$ \\
\hline Other reported symptoms $s^{* * *}$ & $1(3.1)$ & $0(0)$ & $0(0)$ & $4(2.2)$ & $5(2.2)$ \\
\hline Symptom onset date reported & $31(96.9)$ & $8(100)$ & $2(100)$ & $169(91.4)$ & $210(92.5)$ \\
\hline $\begin{array}{l}\leq 5 \text { days between reported symptom onset } \\
\text { and specimen collection }\end{array}$ & $23(74.2)$ & $8(100)$ & $1(50.0)$ & $120(71.0)$ & $152(72.4)$ \\
\hline
\end{tabular}

* Includes 57 participants who received multiple tests and were included more than once in the analysis.

${ }^{\dagger}$ True positive = antigen-positive and RT-PCR-positive; false negative = antigen-negative and RT-PCR-positive; false positive = antigen-positive and RT-PCR-negative; true negative = antigen-negative and RT-PCR-negative; these definitions do not reflect results from viral culture.

$\S$ At university A, real-time RT-PCR was performed using the CDC 2019-nCoV real-time RT-PCR diagnostic panel for detection of SARS-CoV-2.

I At university B, real-time RT-PCR was performed using Thermo Fisher Scientific's TaqPath COVID-19 Combo Kit for detection of SARS-CoV-2.

** One university staff member's child aged 15 years. All other participants were aged $\geq 17$ years.

${ }^{+\dagger}$ Non-Hispanic ethnicity represented for all White, Black/African-American, Asian/Pacific Islander, American Indian/Alaska Native, Other/Unknown/Multiple races.

$\S \S$ Other affiliates were participants who did not mark"student" or "staff" on the questionnaire (they selected "other" or did not respond); the majority of these persons were family members of staff members.

ๆๆ Ever in close contact was defined as within 6 feet for $\geq 15$ minutes of a person with a diagnosis of COVID-19.

*** Other reported symptoms included allergies, cough that is not dry, and difficulty breathing from anxiety.

populations with different characteristics and testing schedules. Second, given the limitations of RT-PCR, some false-positive antigen test results might represent true infections not identified by RT-PCR. Third, the ability to recover infectious virus in culture is limited and decreases for specimens with higher Ct values (8); a lack of virus recovery by culture does not indicate that a person is not infectious. Finally, this investigation evaluated the Sofia SARS Antigen FIA, and cannot be generalized to other FDA-authorized SARS-CoV-2 antigen tests.

Serial testing of asymptomatic and symptomatic persons has been proposed for prevention and control of SARS-CoV-2 transmission $(9,10)$ and is currently being implemented at U.S. colleges and universities and in other congregate settings (3-5). Despite reduced sensitivity compared with real-time RT-PCR, the use of antigen tests for serial testing in these settings, particularly when RT-PCR tests are not available or have a prolonged turnaround time, might still allow rapid identification of infectious persons and control of outbreaks

\section{Summary}

What is already known about this topic?

Antigen tests for SARS-CoV-2 are inexpensive and can return results within 15 minutes, but test performance data in asymptomatic and symptomatic persons are limited.

What is added by this report?

Compared with real-time reverse transcription-polymerase chain reaction (RT-PCR) testing, the Sofia antigen test had a sensitivity of $80.0 \%$ and specificity of $98.9 \%$ among symptomatic persons; accuracy was lower (sensitivity $41.2 \%$ and specificity $98.4 \%$ ) when used for screening of asymptomatic persons.

What are the implications for public health practice?

To account for reduced antigen test accuracy, confirmatory testing with a nucleic acid amplification test (e.g., RT-PCR) should be considered after negative antigen test results in symptomatic persons and positive antigen test results in asymptomatic persons. 
TABLE 2. Sensitivity, specificity, positive predictive value, and negative predictive value of Sofia SARS Antigen Fluorescent Immunoassay compared with real-time reverse transcriptionpolymerase chain reaction (RT-PCR) among asymptomatic and symptomatic persons - two universities, Wisconsin, SeptemberOctober 2020

\begin{tabular}{|c|c|c|c|c|c|c|}
\hline \multirow{3}{*}{$\begin{array}{l}\text { Antigen test } \\
\text { result }\end{array}$} & \multicolumn{6}{|c|}{ RT-PCR result, no. } \\
\hline & \multicolumn{3}{|c|}{ Asymptomatic $(\mathrm{N}=871)$} & \multicolumn{3}{|c|}{ Symptomatic* $(N=227)$} \\
\hline & Positive & Negative & Total & Positive & Negative & Total \\
\hline Positive & 7 & 14 & 21 & 32 & 2 & 34 \\
\hline Negative & 10 & 840 & 850 & 8 & 185 & 193 \\
\hline Total & 17 & 854 & 871 & 40 & 187 & 227 \\
\hline \multicolumn{7}{|c|}{ Test evaluation, \% (95\% Cl) } \\
\hline Sensitivity & \multicolumn{3}{|c|}{$41.2(18.4-67.1)$} & \multicolumn{3}{|c|}{$80.0(64.4-90.9)$} \\
\hline Specificity & \multicolumn{3}{|c|}{$98.4(97.3-99.1)$} & \multicolumn{3}{|c|}{$98.9(96.2-99.9)$} \\
\hline $\begin{array}{l}\text { Positive } \\
\text { predictive value }\end{array}$ & \multicolumn{3}{|c|}{$33.3(14.6-57.0)$} & \multicolumn{3}{|c|}{$94.1(80.3-99.3)$} \\
\hline $\begin{array}{l}\text { Negative } \\
\text { predictive value }\end{array}$ & \multicolumn{3}{|c|}{$98.8(97.8-99.4)$} & \multicolumn{3}{|c|}{$95.9(92.0-98.2)$} \\
\hline
\end{tabular}

Abbreviation: $\mathrm{Cl}$ = confidence interval.

* One or more symptoms reported.
(1). However, antigen-based testing strategies should account for the lower sensitivity and lower PPV when used for asymptomatic screening by considering confirmatory testing with an FDA-authorized NAAT, such as RT-PCR, after a positive antigen test result in an asymptomatic person. Confirmatory testing should also be considered following a negative antigen test result in a person experiencing COVID-19-compatible symptoms. All persons with negative antigen test results should continue to take measures to prevent SARS-CoV-2 transmission, including wearing a mask, reducing contact with nonhousehold members, and getting tested if they experience symptoms or have close contact with someone who has COVID-19. ${ }^{\dagger \dagger}$ Symptomatic persons with negative antigen test results should continue to follow CDC guidance $\$ \$ \$$ for persons who might have COVID-19, including staying home except to get medical care and protecting household members by staying in a separate room, wearing a mask indoors, washing hands often, and frequently disinfecting surfaces.

\footnotetext{
$\dagger \dagger$ https://www.cdc.gov/coronavirus/2019-ncov/prevent-getting-sick/ prevention.html.

$\$ \$ \$$ https://www.cdc.gov/coronavirus/2019-ncov/if-you-are-sick/steps-when-sick.html.
}

FIGURE. Viral culture results among participants with positive Sofia SARS Antigen Fluorescent Immunoassay or positive SARS-CoV-2 real-time reverse transcription-polymerase chain reaction (RT-PCR) results $(n=69),{ }^{*}$ by cycle threshold $(\mathrm{Ct})$ value $^{\dagger}$ and the interval between specimen collection and reported symptom onset or asymptomatic status - university A, Wisconsin, September-October 2020

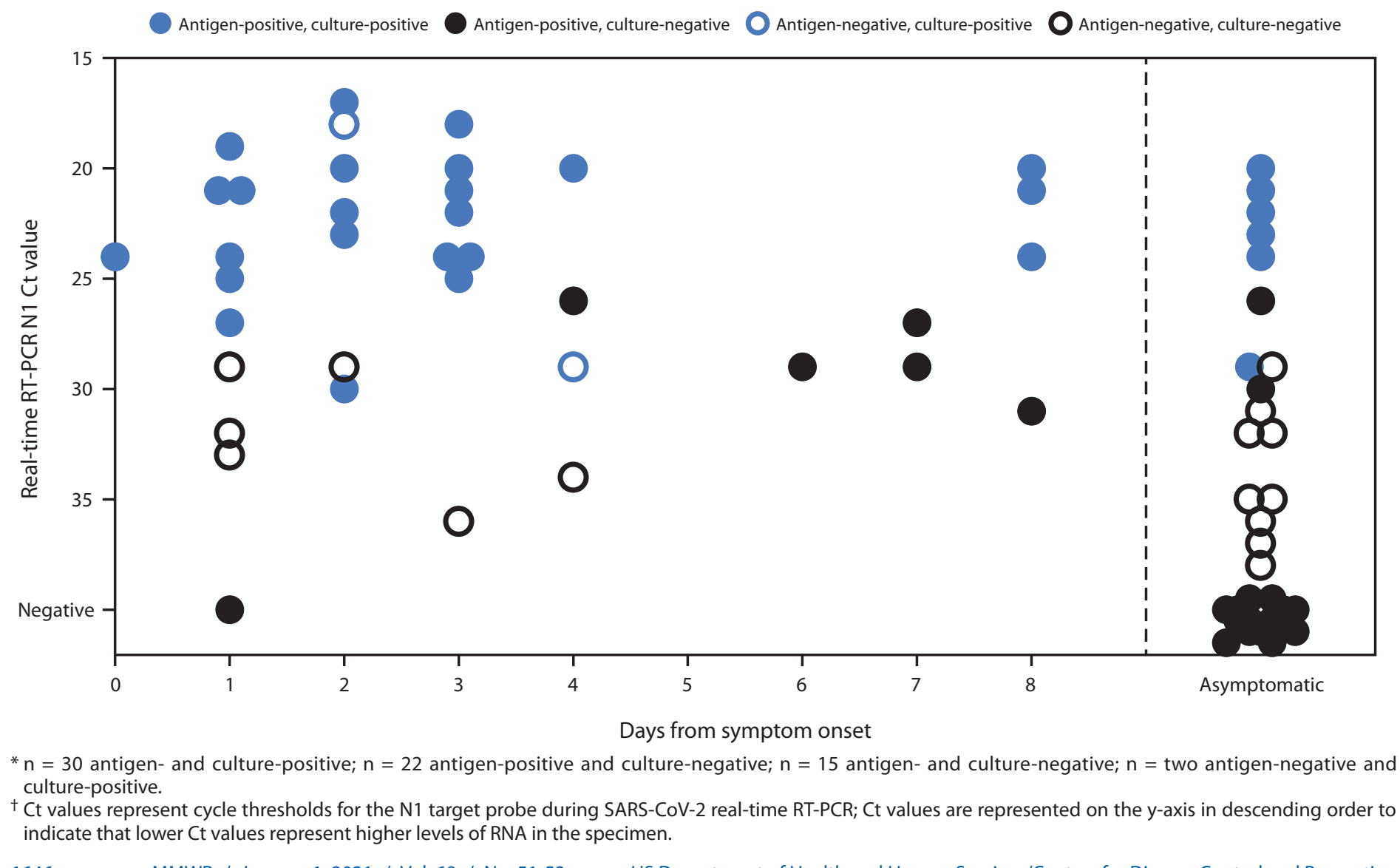




\section{Acknowledgments}

Edward Samuel Rivera, Daniel J. O’Donnell, University of Wisconsin-Oshkosh; Margaret Okomo-Adhiambo, Umesh Parashar, Paul Rota, Lauren Franco, Gerardo Garcia-Lerma, CDC; Neeti Dahal, Wisconsin Veterinary Diagnostic Laboratory-Wisconsin State Laboratory of Hygiene COVID Laboratory, University of Wisconsin-Madison.

\section{CDC COVID-19 Surge Laboratory Group}

Baoming Jiang, CDC; Jan Vinjé, CDC; Amy L. Hopkins, CDC; Eric Katz, CDC; Leslie Barclay, CDC; Mathew Esona, CDC; Rashi Gautam, CDC; Slavica Mijatovic-Rustempasic, CDC; Sung-Sil Moon, CDC; Theresa Bessey, CDC; Preeti Chhabra, CDC; Sarah L. Smart, CDC; Raydel Anderson, CDC; Kay W. Radford, CDC; Gimin Kim, CDC; Dexter Thompson, CDC; Congrong Miao, CDC; Min-hsin Chen, CDC; Lalitha Gade, CDC; Renee Galloway, CDC; Kashif Sahibzada, CDC; Nhien M. Tran, CDC; Srinivasan Velusamy, CDC; HaoQiang Zheng, CDC; Kenny Nguyen, Oak Ridge Institute for Science and Education, Oak Ridge, Tennessee; Claire Hartloge, Oak Ridge Institute for Science and Education, Oak Ridge, Tennessee; Brent Jenkins, Oak Ridge Institute for Science and Education, Oak Ridge, Tennessee; Phili Wong, Oak Ridge Institute for Science and Education, Oak Ridge, Tennessee.

Corresponding author: Ian Pray, ian.pray@dhs.wisconsin.gov.

${ }^{1}$ CDC COVID-19 Response Team; ${ }^{2}$ Epidemic Intelligence Service, CDC; ${ }^{3}$ Wisconsin Department of Health Services; ${ }^{4}$ School of Medicine and Public Health, University of Wisconsin-Madison; ${ }^{5}$ Laboratory Leadership Service, CDC; ${ }^{6}$ Agency for Toxic Substances and Disease Registry, Atlanta, Georgia;

${ }^{7}$ University of Wisconsin-Oshkosh; ${ }^{8}$ University Health Services, University of Wisconsin-Madison; ${ }^{9}$ Wisconsin Veterinary Diagnostic Laboratory, University of Wisconsin-Madison; ${ }^{10}$ Winnebago County Health Department, Oshkosh, Wisconsin; ${ }^{11}$ Wisconsin State Laboratory of Hygiene.

All authors have completed and submitted the International Committee of Medical Journal Editors form for disclosure of potential conflicts of interest. No potential conflicts of interest were disclosed.

\section{References}

1. CDC. Coronavirus disease 2019 (COVID-19): interim guidance for antigen testing for SARS-CoV-2. Atlanta, GA: US Department of Health and Human Services, CDC; 2020. https://www.cdc.gov/ coronavirus/2019-ncov/lab/resources/antigen-tests-guidelines.html

2. Food and Drug Administration. In vitro diagnostics EUAs. Silver Spring, MD: US Department of Health and Human Services, Food and Drug Administration; 2020. https://www.fda.gov/medical-devices/ coronavirus-disease-2019-covid-19-emergency-use-authorizationsmedical-devices/vitro-diagnostics-euas

3. CDC. Coronavirus disease 2019 (COVID-19): guidance for testing, screening, and outbreak response for institutions of higher education (IHEs). Atlanta, GA: US Department of Health and Human Services, CDC; 2020. https://www.cdc.gov/coronavirus/2019-ncov/community/ colleges-universities/ihe-testing.html

4. CDC. Coronavirus disease 2019 (COVID-19): testing guidelines for nursing homes. Atlanta, GA: US Department of Health and Human Services, CDC; 2020. https://www.cdc.gov/coronavirus/2019-ncov/ hcp/nursing-homes-testing.html

5. CDC. Coronavirus disease 2019 (COVID-19): interim considerations for SARS-CoV-2 testing in correctional and detention facilities. Atlanta, GA: US Department of Health and Human Services, CDC; 2020. https://www.cdc.gov/coronavirus/2019-ncov/community/correctiondetention/testing.html

6. Lu X, Wang L, Sakthivel SK, et al. US CDC real-time reverse transcription PCR panel for detection of severe acute respiratory syndrome coronavirus 2. Emerg Infect Dis 2020;26:1654-65. PMID:32396505 https://doi.org/10.3201/eid2608.201246

7. Harcourt J, Tamin A, Lu X, et al. Severe acute respiratory syndrome coronavirus 2 from patient with coronavirus disease, United States. Emerg Infect Dis 2020;26:1266-73. PMID:32160149 https://doi. org/10.3201/eid2606.200516

8. Gniazdowski V, Morris CP, Wohl S, et al. Repeat COVID-19 molecular testing: correlation of SARS-CoV-2 culture with molecular assays and cycle thresholds. Clin Infect Dis 2020; ciaa1616. PMID:33104776 https://doi.org/10.1093/cid/ciaa1616

9. Walke HT, Honein MA, Redfield RR. Preventing and responding to COVID-19 on college campuses. JAMA 2020;324:1727-8. PMID:32991681 https://doi.org/10.1001/jama.2020.20027

10. Paltiel AD, Zheng A, Walensky RP. Assessment of SARS-CoV-2 screening strategies to permit the safe reopening of college campuses in the United States. JAMA Netw Open 2020;3:e2016818. PMID:32735339 https:// doi.org/10.1001/jamanetworkopen.2020.16818 